\title{
PATIENT COMPLAINTS AMONG EMERGENCY ROOM: PATIENTS AT A TEACHING HOSPITAL IN KARACHI
}

\author{
Waris Qidwai, Muhammad Baqir, Syed Sohail Ali and Semi Ayub
}

\begin{abstract}
OBJECTIVES: To study the chief presenting complaints among patients presenting to the Emergency Medical services.

SETTING: This study was conducted at the Emergency Room of Aga Khan University Hospital, Karachi during March and April, 2003.

METHODS: A survey was carried out by the study investigators. This survey included patients who were not very sick and were selected at random. Demographic profiles of the respondents were noted. EPI-info and SPSS computer software programs were used for analysis of the results.

RESULTS: One hundred patients were surveyed. The majority was relatively young, married men and women, well educated and better socio-economically placed. The majority of complaints were related to Gastroenterology, Obstetrics, Gynecology and Orthopedics services.

CONCLUSION: We have documented the chief presenting complaints of emergency room patients. These findings have important implications for medical practice and planners of emergency medical services.
\end{abstract}

KEY WORDS: Morbidity. Emergency Medicine. Emergency Medical Services. Pakistan.

\section{INTRODUCTION}

Emergency Room survey of patient's presenting problems helps in identifying morbidity patterns and disciplines with maximum patient load. There is a scarcity in literature of such reported surveys ${ }^{1,2}$. This is probably because such surveys are used to plan and improve services at the centers where they are conducted and are not reported. It is important to explore the utilization of such surveys for improvement of services offered to the patients.

There are reports of overcrowding at the emergency departments $^{3,4}$ and therefore prior planning and organization of such services is even more important. Prioritizing the services that can be offered at the emergency department is important, in the presence of limited resources. Surveys of patient complaints can help in resource allocation and service development in the emergency departments.

We established a need to study the presenting complaints of patients presenting with a medical emergency at our hospital.

\section{PATIENTS AND METHODS}

A survey was carried out at the Emergency Room, The Aga Khan University hospital in Karachi, Pakistan, during March and April 2003. It is a teaching facility, providing tertiary level facilities in the private sector and is managed by trained Emergency Room physicians. About one hundred patients are treated at the Emergency Room daily.

This survey included the demographic profile of the respondents and was conducted by the study investigators. It included patients who were not very sick and were selected at random. EPI-info and SPSS computer software programs were used for analysis of the results.

\section{RESULTS}

One hundred Emergency Room patients were surveyed. Mean age of the patients was 42.72 years and most of them were married. More details regarding the demographic profile of the respondents is listed in Table-I. Chief presenting complaints of emergency room patients are listed in Table-II. 
TABLE I

DEMOGRAPHIC PROFILE OF THE PATIENTS $(n=100)$

\begin{tabular}{|l|c|}
\hline \multicolumn{1}{|c|}{ Parameter } & No. of Percent \\
\hline Sex: & $54(54)$ \\
\hline Males & $46(46)$ \\
\hline Females & $42.72(17.39)$ \\
\hline Mean Age (SD*) & \\
(In years) & $22(22)$ \\
\hline Marital Status: & $75(75)$ \\
\hline Single & $02(02)$ \\
Married & $01(01)$ \\
Divorced & \\
Widow & $07(07)$ \\
\hline Educational Status & $05(05)$ \\
\hline Illiterate & $15(15)$ \\
Primary & $32(32)$ \\
Matriculation & $36(36)$ \\
Intermediate & $05(05)$ \\
Graduate & \\
Post-graduate & $06(06)$ \\
\hline Occupational status & $14(14)$ \\
\hline Unemployed & $18(18)$ \\
Self employed & $05(05)$ \\
Private service & $35(35)$ \\
Government service & $10(10)$ \\
Housewife & $12(12)$ \\
\hline Student & \\
Retired & \\
\hline
\end{tabular}

* Standard deviation

TABLE II

PRESENTING CHIEF COMPLAINTS OF EMERGENCY ROOM PATIENTS $(\mathrm{N}=100)$

\begin{tabular}{|l|c|}
\hline \multicolumn{1}{|c|}{ Presenting Complaint } & Percentage \\
\hline $\begin{array}{l}\text { Abdominal pain vomiting and } \\
\text { diarrhea }\end{array}$ & $35(35)$ \\
\hline Orthopedic problems & $11(11)$ \\
\hline Obstetrics \& Gynecologic problems & $11(11)$ \\
\hline Shortness of Breath & $08(08)$ \\
\hline Fever & $07(07)$ \\
\hline Trauma & $07(07)$ \\
\hline Chest pain & $06(06)$ \\
\hline Dizziness & $05(05)$ \\
\hline Diabetes Mellitus & $02(02)$ \\
\hline Urinary retention & $02(02)$ \\
\hline Cough & $02(02)$ \\
\hline Hypertension & $01(01)$ \\
\hline Hemorrhoids & $01(01)$ \\
\hline Constipation & $01(01)$ \\
\hline Jaundice & $01(01)$ \\
\hline
\end{tabular}

\section{DISCUSSION}

We have documented the presenting chief complaints of emergency room patients. It was a pilot project and included a hundred patients. We cannot generalize the findings, since our study population was more educated and better placed socio-economically than the rest of the population in our country. The Emergency Room of Aga Khan University is considered to be among the best in the city, with the result that a selected group of patients use the facility. Nonetheless, the findings do offer us information with regard to the common emergency room patient's clinical presentations. Such information can help us better plan the services that we offer at the facility. It would be better if such a survey is carried out on an ongoing basis, since it will not only provide information on the spectrum of patient complaints but will also the ensuing trends. It would also be useful to have information with regards to patient complaints that could not be offered treatment at the facility and had to be referred elsewhere.

We have found the majority of complaints were related to Gastroenterology, Obstetrics, Gynecology and Orthopedics services. We have not found upper respiratory infections cases since they report to the out-patient services. Surveys done on pediatric emergency patient population have found respiratory and gastrointestinal problems as the main presenting complaints ${ }^{1}$.

Surveys are reported that have been conducted with the aim to improve patient care services ${ }^{5,6}$

There is evidence to show increased patient satisfaction in relation to more frequent patient complaints $^{7}$. This shows an inherent tendency to improve those services which are more frequently utilized.

Patient satisfaction is seid to vary with the presenting complaint of patients ${ }^{8}$, thereby emphasizing it association and importance.

Information on the types of emergency room patient complaints can also help develop "triage" guidelines? Development of such guidelines and services will reduce load on the emergency department services and allow more focused care where it is required.

\section{CONCLUSION}

We have documented the chief presenting complaints of emergency room patients. These findings have important implications for medical practice and planners of emergency medical services. 


\section{REFERENCES}

1. Kibirige MS, Edmond K, Kibirige JI, Rahman S A. Seven year experience of medical emergencies in the assessment unit. Arch Dis Child. 2003;88:125-9.

2. Paddock K, Hirdes JP. Acute health care service use among elderly home care clients. Home Health Care Serv Q. 2003;22:75-85.

3. Schneider SM, Gallery ME, Schafermeyer R, Zwemer FL. Emergency department crowding: a point in time. Ann Emerg Med. 2003:42:167-72.

4. Fields WW. Calculus, chaos, and other models of emergency department crowding. Ann Emerg Med. 2003; 42:181-4.

5. Schwappach DL, Koeck CM. Improving patientprovider communications: a web- access national health-care survey panel. Health Expect. 2003;6:269-72.

6. Qidwai W, Dhanani $\mathrm{RH}$, Khan FM. Implications for the practice of a patient expectation and satisfaction survey at a teaching hospital in Karachi, Pakistan. J Pak Med Assoc. 2003;53:122-5.
7. Kuisma M, Maatta T, Hakala T, Sivula T, NousilaWiik M. Customer satisfaction measurement in emergency medical services. Acad Emerg Med. 2003;10:812-5.

8. Buller-Close K, Schriger DL, Baraff LJ. Heterogeneous effect of an Emergency Department Expert Charting System. Ann Emerg Med. 2003;4:644-52.

9. Summers M, Happell B. Patient satisfaction with psychiatric services provided by a Melbourne tertiary hospital emergency department. J Psychiatr Ment Health Nurs. 2003 ; 10:351-7.

Correspondence:

Dr. Wartis Qidwai

Associate Professor

Department of Family Medicine

The Aga Khan University

Stadium Road, P.O. Box: 3500

Karachi 74800, Pakistan

Fax: (9221) 493-4294, 493-2095

Telephone: (9221) 48594842/4930051 Ext. 4842

E-Mail: waris@akunet.org 